DOI: 10.15587/2706-5448.2021.237231

Article type «Reports on Research Projects»

\section{Evgen Opanasyuk, Dmytro Beherskyi, Mykola Mozharovskyi, Ivan Vitiuk}

\title{
RESEARCH OF THE IMPACT OF VIBRATION ON THE EFFICIENCY OF DISSEMINATION OF LOOSE PLANT PRODUCTS FROM THE MOTOR VEHICLE BODIES
}

The object of research is the process of unloading bulk crop products from the bodies of dump trucks, the subject of the study is the dependence of the energy consumption of unloading on the properties of products when exposed to vibration. This dependence is understood as a change in the properties of bulk products, such as internal friction and the angle of repose, in the direction of decreasing, providing a decrease in the angle of lift of the body. One of the most problematic areas is the lack of objective information on the dependence of the required lifting angles of the dump truck body when unloading fine-grained crop products when exposed to vibrations. There is also insufficient information on the dependence of these angles on vibration frequency for each of the products.

In the course of the study, an experimental method was used to determine the angles of natural bevel for different crops without and under the influence of vibrations of different frequencies on the reference area. The proposed development makes it possible to quantitatively assess the degree of influence of vibrations, their frequencies and time of impact on the frictional properties of bulk crop products. The degree of reduction of internal friction in these products and the maximum angles of lifting the body required for its unloading were experimentally determined, and numerical data were obtained on their reduction under the influence of vibrations. The results obtained allow to consider it an effective tool for obtaining objective information about the effect of vibrations on the characteristics of internal friction of bulk crop products. This made it possible to determine the degree of influence of the lift angle of the dump truck body during unloading and to reduce energy costs. In contrast to the existing ones, the proposed development makes it possible to differentiate these angles depending on the frequency and time of exposure to vibration, as well as on a specific product. Certain parameters make it possible to regulate them to achieve minimum energy consumption.

Keywords: bulk crop products, internal friction, angle of repose, body lift angle, dump truck, loading and unloading operations.

\section{How to cite}

Opanasyuk, E., Beherskyi, D., Mozharovskyi, M., Vitiuk, I. (2021). Research of the impact of vibration on the efficiency of dissemination of loose plant products from the motor vehicle bodies. Technology Audit and Production Reserves, 4 (1 (60)), 25-30. doi: http://doi.org/10.15587/2706-5448.2021.237231

\section{Introduction}

Significant production of cereals in the world (in 2019, 2708.7 million tons [1] were produced) requires significant costs for their transportation and processing, which is associated with energy costs. At the same time, taking into account the peculiarities of a free-flowing unbound medium, which is the grain production of crop production, under the influence of vibration [2-4], makes it possible to reduce the energy intensity of these processes. In these and many other studies, it has been proved that the action of vibration in this case leads to such phenomena as pseudo-boiling or fluidization of the medium, causing a significant decrease in the coefficient of internal friction. This change can be used, in particular, in the means for moving, processing grain and facilitating their unloading from dump trucks by reducing the angle of lift of a flat bottom body required for unloading. The use of this phenomenon is advisable when creating specialized dump trucks, grain carriers, engaged in the mass transportation of grain crops. This usually requires the use of additional equipment to generate vibration. Let's consider this issue on the example of vehicles in Ukraine.

According to the State Statistics Service of Ukraine [5], the grain harvest in 2019 (corn, wheat, barley, rye, millet, legumes, peas, etc.) amounted to almost 75/0 8 million tons against 70.1 million tons in 2018. In addition, sunflower harvested 14.5 million tons, soybeans -3.7 million tons, rapeseed - more than 2.6 million tons. Of course, in this case, it becomes necessary to move these goods between 
the subjects of activity (producers, processors, custodians, processors and consumers), which is practically impossible to carry out without the participation of road transport. In 2019, a total of 190,041.19 thousand tons of various goods were transported by road. Of this amount 24366.22 thousand tons or $12.82 \%$ of agricultural products, hunting and forestry, fish and other fishery products. Of these 24366.22 thousand tons, the share of grain is 19115.28 thousand tons or $78.45 \%$.

On vehicles in the most time-consuming and difficult work include loading and unloading operations, which are an integral part of the transport process. The average level of mechanization of loading and unloading operations in road transport is approximately $70 \%$. This is much lower than the level of mechanization of this kind of work on sea, rail and river modes of transport.

If to consider bulk cargo (grain crops, feed, mineral fertilizers, sand, soil, crushed stone, gravel, etc.), then in the total volume of cargo transported by vehicles, they are approximately $80 \%[6,7]$.

Ripe crops of crop production are incoherent and have the properties of a free-flowing substance. Known grains and seeds have a rounded shape and smooth surface (millet, peas, vetch, soybeans). If, in addition to this, the seeds are, in comparison with others, insignificant in size (clover, mustard, camelina), then the term fluidity is applied to their properties. The grains are oblong, less free-flowing. Self-flow of grain creates favorable conditions for a significant simplification of loading and unloading storage facilities and vehicles.

For transportation of grain products, in most cases, dump trucks are used. In dump trucks, gravity unloading is mainly used. In this case, the lift angle of the body must exceed the angle of repose (for the loads given in Table 1, this angle, depending on the crop, should be from 24 to 42 degrees).

Table 1

Angles of repose of some crops, degrees

\begin{tabular}{|c|c|c|c|}
\hline Culture & Angle of repose & Mass $1 \mathrm{~m}^{3}, \mathrm{~kg}$ & Wellness, $\%$ \\
\hline Wheat & $23-38(32)$ & $730-840$ & $35-45$ \\
\hline Rye & $23-38(34)$ & $680-750$ & $35-45$ \\
\hline Barley & $27-48(36)$ & $580-700$ & $45-5550-70$ \\
\hline Oats & $31-54(42)$ & $400-550$ & $50-70$ \\
\hline Millet & $20-27(24)$ & $680-730$ & $30-50$ \\
\hline Peas & $22-28(26)$ & $750-800$ & $40-45$ \\
\hline Corn & $30-40(37)$ & $680-820$ & $35-55$ \\
\hline Sunflower & $31-45(41)$ & $400-550$ & $50-65$ \\
\hline Say & $25-32(29)$ & $700-740$ & $30-45$ \\
\hline Linen & $27-34(32)$ & $580-680$ & $35-45$ \\
\hline
\end{tabular}

Note: the angle of repose is indicated in brackets, it is taken in calculations for planning post-harvest processing of grain and seeds

The numerical values of these angles are given for quasistatic conditions, but, as is known, the internal cohesion of incoherent particles of bulk cargo and the angle of internal friction depend on the parameters of the frequency and vibration acceleration of the vibration fuel to the load. Due to this effect, it is possible to reduce the lift angle of the body and, accordingly, reduce the time and energy consumption when unloading it. The same method $[8,9]$ of combined gravitational-vibration unloading can be used when unloading vehicles with on-board universal platforms using dumpers.

The use of vibration technologies is due to the simplicity of the design of vibration devices, their compactness, high energy consumption and a wide range of regulation of operating parameters.

Acceleration of unloading of bodies with a decrease in energy consumption in modern vehicles is provided by the following methods: creation of oscillations of the body at the end of unloading, unloading using an additional shell in the body and vibration shock devices [8, 10, 11].

Therefore, based on the foregoing, it is possible to conclude that the use of vibration technologies to accelerate the unloading of vehicles with bulk materials is an urgent task.

Thus, the object of research is the process of unloading bulk crop products from the bodies of dump trucks. And the aim of research is to conduct experimental studies of the properties of incoherent grain products of crop production, affecting the indicators of the process of unloading vehicle bodies and assessing their impact on these indicators.

\section{Methods of research}

During the research, the methods of natural experiment and methods of physical modeling were used.

To create a structure to facilitate unloading of dump truck bodies, it is advisable to conduct a number of analytical and experimental studies. The program of these studies should provide for the determination of the optimal body lift angles depending on the properties of the load under the influence of vibration. This will make it possible to estimate the energy consumption when unloading the body during the implementation of the proposed measures. Taking into account the high cost and the influence of extraneous factors on the results of field experimental studies, it is advisable to use the method of physical modeling to achieve this goal, for which the experimental setup was improved and used [9, 12]. In Fig. 1 shows a schematic diagram and a general view of this unit.
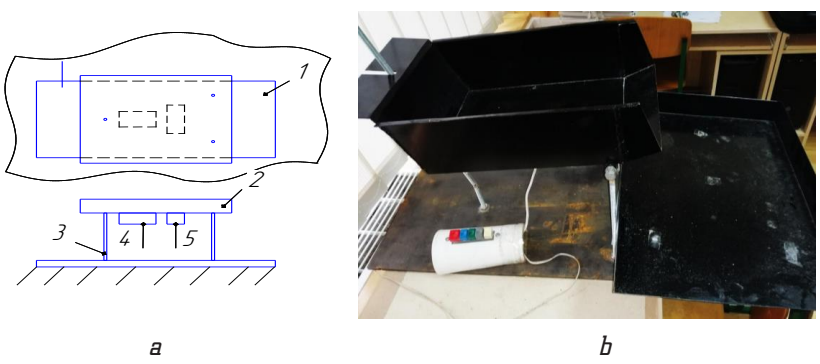

Fig. 1. Unit for studying the properties of bulk crop products under the influence of vibrations: $a$ - schematic diagram (1 - bearing base, 2 - working surface (bottom of the body), 3 - elements connecting the working surface with the supporting base, 4 - accelerometer, 5 - device for creating vibrations; $b$ - general view

An accelerometer and a device for creating vibrations with a switch for the rotation frequency of the electric motor armature are shown in Fig. 2.

Registration and accumulation of the results of experimental studies at different vibration frequencies of the bottom of the working surface were carried out using a computer with simultaneous video recording of the processes. 


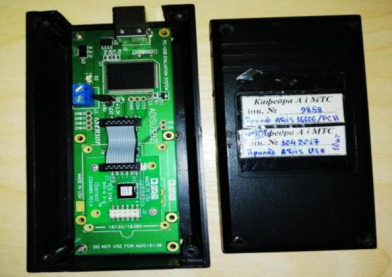

a

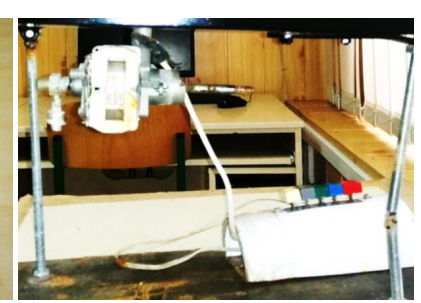

$b$

Fig. 2. Additional body equipment:

$a$ - accelerometer; $b$ - device for creating vibrations

The dependence of the geometric parameters of a loosely poured cone of bulk agricultural material (grain crops) under the influence of vibrations was investigated. Studies were carried out for crops such as millet, rye, wheat, barley, corn, sunflower seeds (Fig. 3).

Research was carried out in turn with all cultures. Grain of various crops in turn freely poured out through a hole with a diameter of $20 \mathrm{~mm}$ from a height of $20-30 \mathrm{~mm}$ from the surface of the already poured, forming a hill of regular shape in the form of a cone. The angle formed at the base of which the angle of repose is proportional to the internal friction coefficient. Dumping of agricultural bulk material took place in the absence of vibration. The results of determining the angles of repose for these types of grain are shown in Fig. 4.

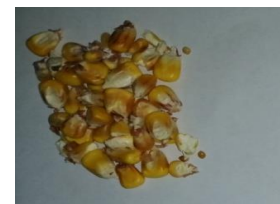

a

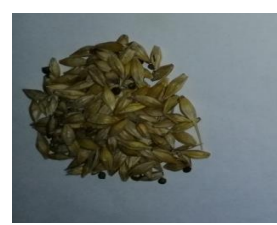

d

Fig. 3. Appearance of bulk agricultural material: $a$ - corn; $b$ - millet; $c$ - wheat; $d$ - rye; $e$ - sunflower seeds; $f$ - barley

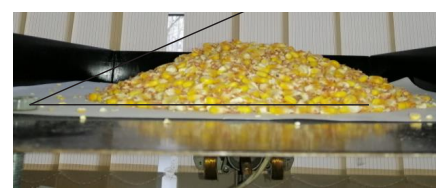

a
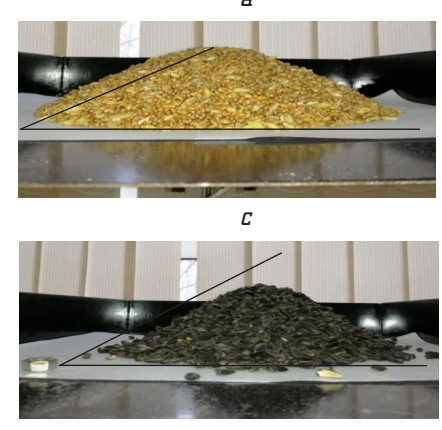

e

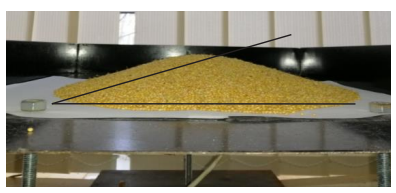

$b$

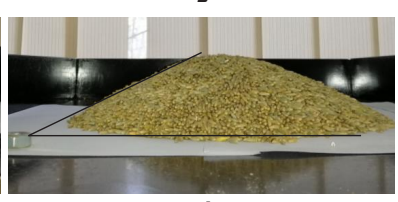

d

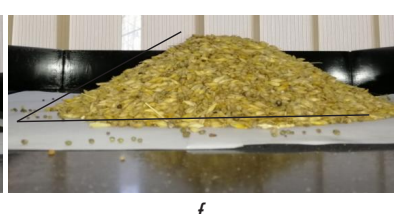

$f$

Fig. 4. The initial shape of a cone formed without vibrations: $a$ - corn; $b$ - millet; $c$ - wheat; $d-$ rye; $e$ - sunflower seeds; $f$ - barley
To obtain reliable results of determining the angles of repose, each experiment was carried out three times and, according to their results, the average values of the angles were determined, which are shown in the diagram in Fig. 5.

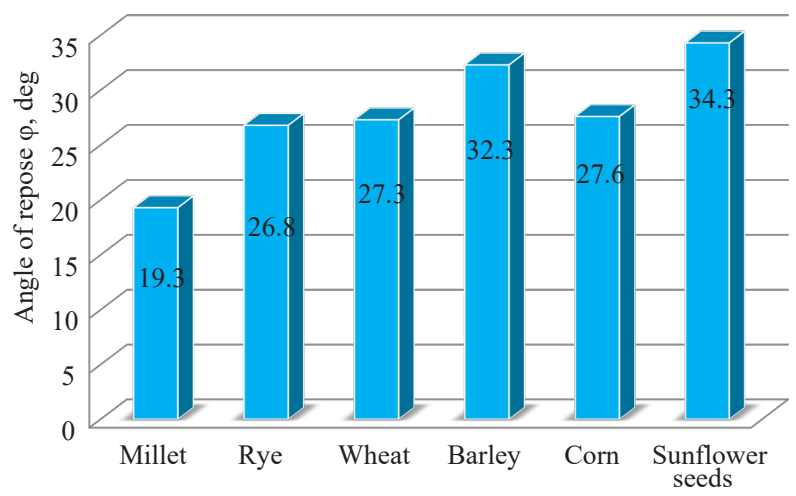

Fig. 5. Average values of angles of repose $\varphi$ for cereals (seeds)

The maximum deviations in the results of each experiment ranged from $2.7 \%$ (wheat) to $4.3 \%$ (sunflower seeds). The difference in the values of the deviations can be explained by the difference in the size, shape and roughness of the grains.

\section{Results of experiments and discussion}

To assess the influence of vibrations on the indicators of internal friction of the grain mass, a number of experiments were carried out to determine the change in the angles of repose in the presence of oscillations of the support platform (Fig. 2, b). A typical oscillogram of changes in the vibration acceleration of the support platform and the results of the influence of vibrations for $10 \mathrm{~s}$ on the shape of a millet cone (in comparison with what is shown in Fig. 3, b) are shown in Fig. 6.

Table 2 shows the results of the experimental determination of the change in the angle of internal friction in time $(0 \mathrm{~s}, 1 \mathrm{~s}, 2 \mathrm{~s}, 3 \mathrm{~s}, 4 \mathrm{~s}, 5 \mathrm{~s})$ from the beginning of the vibration action and from the vibration frequency $v$ for the studied types of grain crops.

Analysis of the results of experimental studies given in Table 2 indicates that under the conditions of the experiments and in a given range of vibration frequencies, the intensity of the decrease in the angle of internal friction of the considered grain crops decreases with the action of vibrations. At the same time, at the beginning of the process, the reduction proceeds more intensively than at the end, and practically loses its effectiveness for $4 \mathrm{~s}$. The intensity of the decrease in the angle of internal friction of various types of cereals again depends on the size, complexity of the shape and roughness of the grains. In addition, for $4 \mathrm{~s}$, under the influence of vibrations, the angle of internal friction decreases by an average of $4-6$ times. This gives grounds to assert that due to the vibration influence on the cargo of this category, it is possible to significantly reduce the energy consumption for its unloading by tilting the body to smaller angles.

To confirm the above, a number of experiments were carried out with all the studied types of crops when unloading a dump truck body model without vibration action and with vibration action on the load. As an example, in Fig. 7 shows the lifting angles of the body at the beginning of unloading corn grain (Fig. 7, a) and at its completion (Fig. 7, b). 


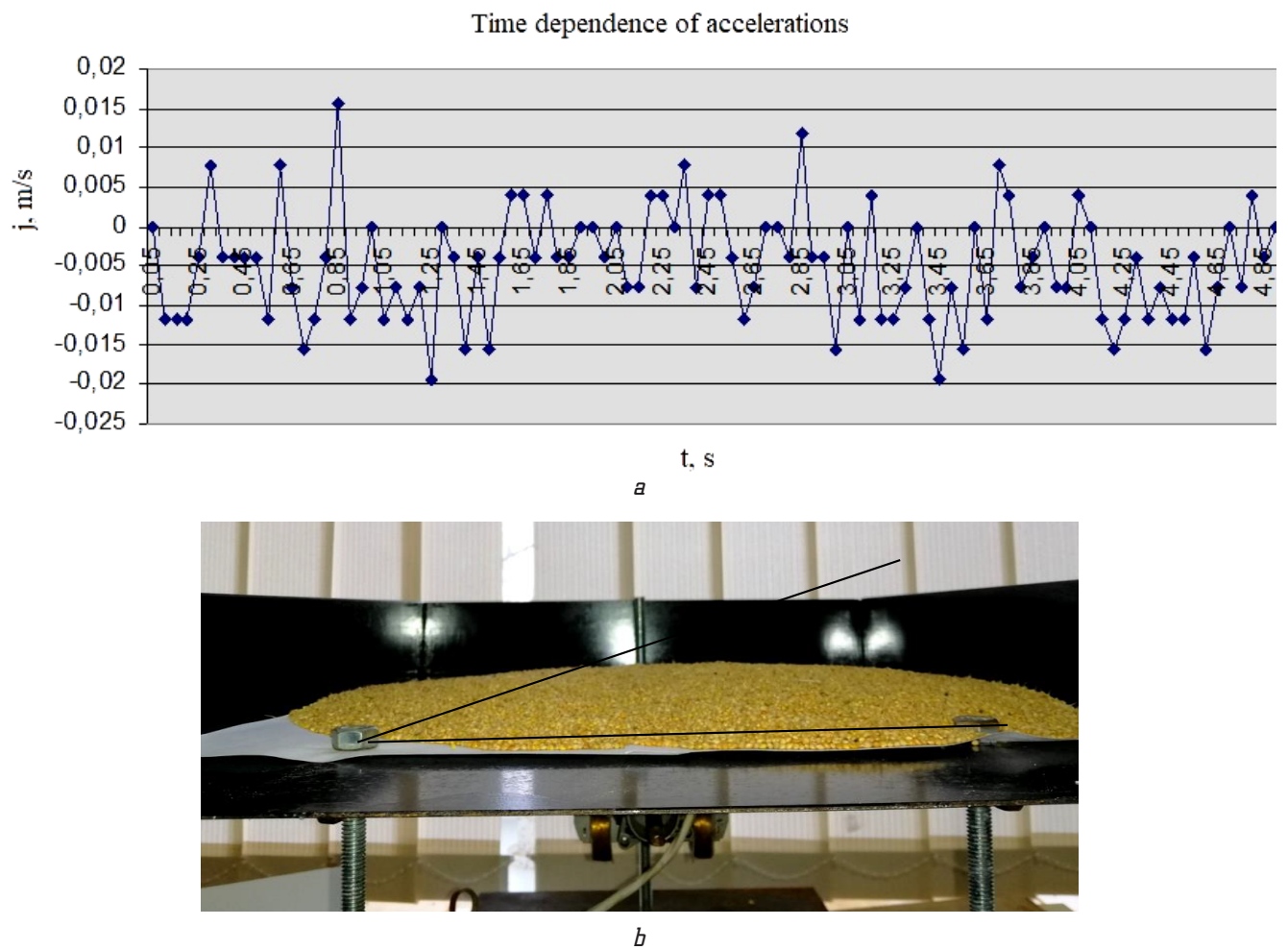

Fig. 6. Typical test results: $a$ - oscillogram of vibration acceleration changes in time; $b$ - general view of the cone (millet) after exposure to vibrations

Table 2

Angle of repose $\varphi$ value for cereals (seeds) under vibration

\begin{tabular}{|c|c|c|c|c|c|c|}
\hline \multicolumn{7}{|c|}{ Internal friction angle $\varphi$ for millet } \\
\hline \multirow{2}{*}{$\begin{array}{c}\text { Frequency } \\
\text { v, Hz }\end{array}$} & \multicolumn{6}{|c|}{ Vibration action time, $s$} \\
\hline & 0 & 1 & 2 & 3 & 4 & 5 \\
\hline$v_{1}=14 \mathrm{~Hz}$ & 20 & 14 & 7 & 5 & 5 & 5 \\
\hline$v_{1}=14.5 \mathrm{~Hz}$ & 19 & 11 & 8 & 4 & 3 & 3 \\
\hline$v_{1}=16.5 \mathrm{~Hz}$ & 19 & 13 & 9 & 5 & 5 & 5 \\
\hline \multicolumn{7}{|c|}{ Internal friction angle $\varphi$ for гуе } \\
\hline$v_{1}=14 \mathrm{~Hz}$ & 25 & 17 & 10 & 8 & 5 & 4 \\
\hline$v_{1}=14.5 \mathrm{~Hz}$ & 26 & 16 & 10 & 9 & 7 & 5 \\
\hline$v_{1}=16.5 \mathrm{~Hz}$ & 27 & 16 & 11 & 10 & 8 & 6 \\
\hline \multicolumn{7}{|c|}{ Internal friction angle $\varphi$ for wheat } \\
\hline$v_{1}=14 \mathrm{~Hz}$ & 28 & 17 & 13 & 10 & 6 & 6 \\
\hline$v_{1}=14.5 \mathrm{~Hz}$ & 27 & 16 & 10 & 8 & 6 & 5 \\
\hline$v_{1}=16.5 \mathrm{~Hz}$ & 27 & 15 & 13 & 9 & 6 & 6 \\
\hline \multicolumn{7}{|c|}{ Internal friction angle $\varphi$ for barley } \\
\hline$v_{1}=14 \mathrm{~Hz}$ & 31 & 19 & 13 & 10 & 7 & 6 \\
\hline$v_{1}=14.5 \mathrm{~Hz}$ & 33 & 20 & 13 & 9 & 6 & 5 \\
\hline$v_{1}=16.5 \mathrm{~Hz}$ & 33 & 18 & 12 & 9 & 6 & 6 \\
\hline \multicolumn{7}{|c|}{ Internal friction angle $\varphi$ for согп } \\
\hline$v_{1}=14 \mathrm{~Hz}$ & 25 & 15 & 10 & 8 & 7 & 7 \\
\hline$v_{1}=14.5 \mathrm{~Hz}$ & 28 & 16 & 10 & 8 & 7 & 5 \\
\hline$v_{1}=16.5 \mathrm{~Hz}$ & 30 & 16 & 10 & 7 & 6 & 5 \\
\hline \multicolumn{7}{|c|}{ Internal friction angle $\varphi$ for sunflower seeds } \\
\hline$v_{1}=14 \mathrm{~Hz}$ & 36 & 20 & 14 & 11 & 18 & 7 \\
\hline$v_{1}=14.5 \mathrm{~Hz}$ & 32 & 16 & 10 & 8 & 6 & 6 \\
\hline$v_{1}=16.5 \mathrm{~Hz}$ & 35 & 18 & 11 & 9 & 6 & 5 \\
\hline
\end{tabular}

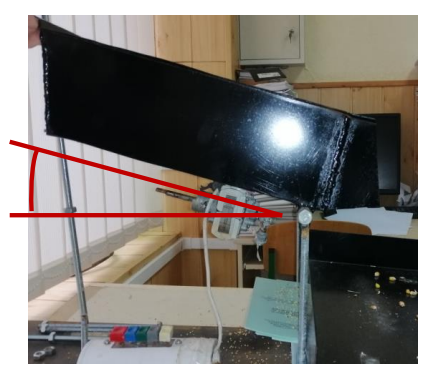

a

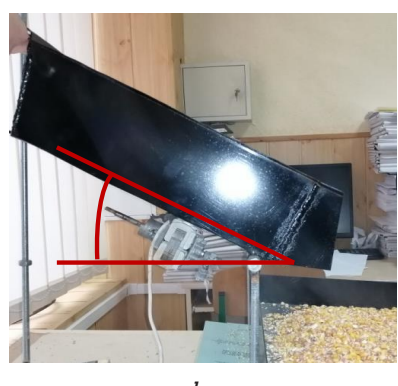

$b$
Fig. 7. Position of the body when unloading corn grain in the presence of vibration of the bottom of the body: $a$ - beginning of unloading; $b$ - end of unloading

Experimental studies were carried out with all bulk crop products accepted for consideration. The angle of inclination of the body at the beginning of the pouring of the substance was measured both in the absence of vibrations and in their presence, at three different vibration frequencies. The number of repetitions of one experiment for one raw material at one speed is 3 (the average values of the measurement results are given in Table 3 ).

Given in Table 3 the results of experimental studies indicate that, under the influence of vibrations, the tilt angles of the body model are significantly reduced, at which both the beginning and the complete unloading of the cargo platform is carried out. Moreover, this dependence is inversely proportional to the vibration frequency. So, when unloading these grain crops, full unloading (with an immovable bottom) in the presence of vibrations is carried out at a body tilt angle less than 20.7-39.4\%.

An example of the graphical dependence of the angle of inclination of the dump truck body model $\alpha$ on the vibration frequency when unloading millet is shown in Fig. 8. 
Dependence of the tilt angle of the dump truck body model $\alpha$ from the vibration frequency of the underbody

\begin{tabular}{|c|c|c|c|c|c|c|c|c|}
\hline \multirow{3}{*}{ Grain } & \multicolumn{6}{|c|}{ Angle $\alpha$ with vibration } & \multirow{2}{*}{\multicolumn{2}{|c|}{ Angle $\alpha$ without vibration }} \\
\hline & \multicolumn{2}{|c|}{1 speed } & \multicolumn{2}{|c|}{2 speed } & \multicolumn{2}{|c|}{3 speed } & & \\
\hline & $\begin{array}{c}\text { start } \\
\text { of unloading }\end{array}$ & $\begin{array}{l}\text { end } \\
\text { of unloading }\end{array}$ & $\begin{array}{c}\text { start } \\
\text { of unloading }\end{array}$ & $\begin{array}{c}\text { end } \\
\text { of unloading }\end{array}$ & $\begin{array}{c}\text { start } \\
\text { of unloading }\end{array}$ & $\begin{array}{l}\text { end } \\
\text { of unloading }\end{array}$ & $\begin{array}{c}\text { start } \\
\text { of unloading }\end{array}$ & $\begin{array}{c}\text { end } \\
\text { of unloading }\end{array}$ \\
\hline Millet & 11 & 27 & 10 & 23 & 10 & 20 & 13 & 33 \\
\hline Rye & 10 & 26 & 9 & 24 & 10 & 23 & 15 & 32 \\
\hline Wheat & 12 & 25 & 11 & 23 & 10 & 22 & 15 & 30 \\
\hline Barley & 12 & 26 & 11 & 24 & 10 & 23 & 14 & 29 \\
\hline Corn & 12 & 20 & 10 & 18 & 10 & 19 & 15 & 27 \\
\hline Sunflower seeds & 12 & 27 & 10 & 24 & 10 & 23 & 15 & 33 \\
\hline
\end{tabular}

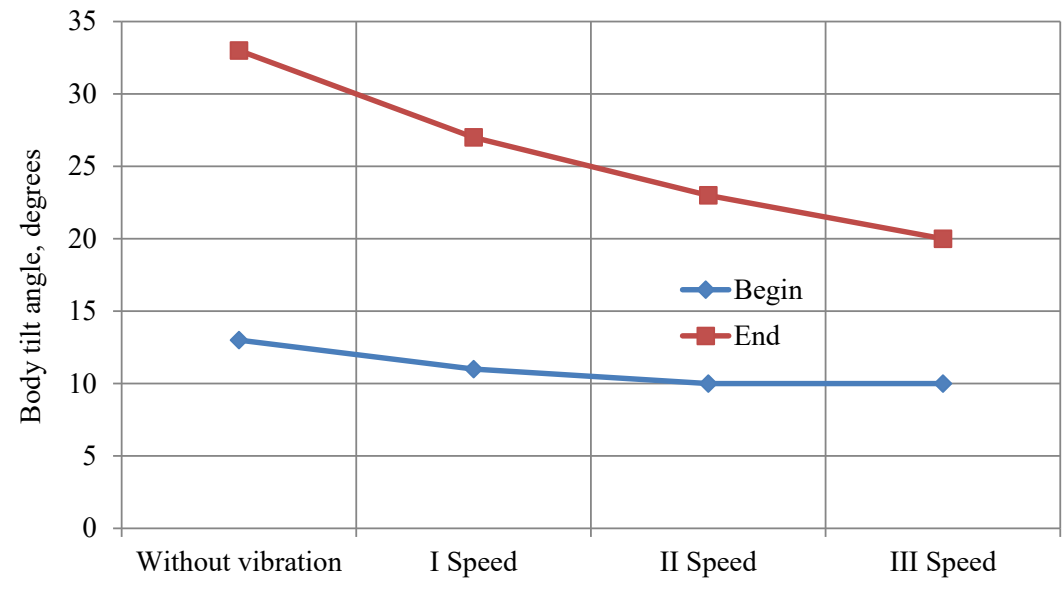

Fig. 8. Dependence of the tilt angle of the dump truck body model $\alpha$ on the vibration frequency when unloading millet

The dependences of the tilt angles of the dump truck body model $\alpha$ on the vibration frequency during unloading of other considered crop products have a similar character.

It should be noted that to unload the dump truck body, the angle of its ascent should not be less than the angle of repose, otherwise the material will not be unloaded under the influence of gravitational forces. At the same time, it is known that the angle of repose for bulk materials changes in the direction of decrease under the influence of vibrations. The introduction of this method of facilitating the unloading of grain crops will reduce energy costs and improve the lateral stability of the dump truck by reducing the body lift angle and the height of the common center of mass of the load and the dump truck itself.

In this work, the frictional properties of cereals such as corn, millet, wheat, rye, sunflower grains (unpeeled) and barley are investigated. At the same time, no attention has been paid to such crop products as buckwheat, rice, rapeseed, peas and others. In addition, the issues of the influence of grain moisture on the indicators of its internal friction were considered. In addition, it should be noted the need to study the effect on the efficiency of unloading of the structure of the bottom of the dump truck body, the device for creating vibrations and its location. Of course, this can be taken into account in subsequent studies in this direction.

\section{Conclusions}

Based on the analysis of the data [8, $11,12]$ and the obtained research results, as a conclusion, it can be argued that when using the gravitational method of unloading car bodies, the use of vibrations of the bottom of the body leads to a decrease in the body lift angle required for unloading. This allows to reduce the time and energy costs for unloading bulk crop products.

At the same time, given the massive use of road transport in the transportation of this category of goods, this will lead to some growth in the production and economic performance of road transport involved in this transportation.

As a result of the experimental studies, it was found that the use of vibration makes it possible to reduce the lift angle of the body of a dump truck when unloading grain products:

- millet - by $39.4 \%$;

- rye - by $28.1 \%$;

- wheat - by $26.7 \%$;

- barley - by $20.7 \%$;

- corn - by $29.6 \%$;

- sunflower - by $30.3 \%$.

The results of these studies can be used in the transportation of agricultural products to reduce the time and energy consumption when performing unloading operations.

\section{References}

1. Shyrokyi, H. M. (2020). Natsionalnyi instytut stratehichnykh doslidzhen. Svitovyi rynok zernovykh kultur v umovakh pandemii koronavirusu. Available at: https://niss.gov.ua/sites/default/ files/2020-07/svitovyi-rynok-zerna-1.pdf

2. Gidaspow, D. (1994). Multiphase flow and fluidization: Continuum and kinetic theory descriptions. Boston: Academic Press Inc., 211. doi: http://doi.org/10.1016/c2009-0-21244-x

3. Huilin, L., Yongli, S., Yang, L., Yurong, H., Bouillard, J. (2001) Numerical Simulations of Hydrodynamic Behaviour in Spouted Beds. Chemical Engineering Research and Design, 79 (5), 593-599. doi: http://doi.org/10.1205/02638760152424370

4. Kunii, D., Levenspiel, O. (1991). Fluidization Engineering. Butterworth-Heinemann, 491. 
5. Perevezennia vantazhiv avtomobilnym transportom za vydamy vantazhiv za 2019 rik. Derzhavna sluzhba statystyky Ukrainy. Available at: http://www.ukrstat.gov.ua/operativ/operativ2019/ $\mathrm{tr} / \mathrm{pv}$ avt/pv_avt_u/pv_avt12m19_u.htm

6. Derzhavna sluzhba statystyky Ukrainy. Available at: http:// www.ukrstat.gov.ua

7. Hrechka, O. V. (2015). Statystychnyi analiz rynku posluh avtomobilnoho transportu. Kyiv, 20.

8. Iskovych-Lototskyi, R. D., Ivanchuk, Ya. V. (2008). Pidvyshchennia efektyvnosti rozvantazhennia materialiv pid diieiu periodychnykh udarnykh impulsiv. Vibratsii v tekhnitsi $i$ tekhnolohiiakh, 2 (51), 8-11.

9. Opanasiuk, Ye. H., Beherskyi, D. B., Opanasiuk, O. Ye. (2018). Pidvyshchennia efektyvnosti rozvantazhuvalnykh robit nezviaznykh budivelnykh materialiv iz kuzoviv samoskydiv. Naukovi notatky Mizhouzioskyi zbirnyk (za haluziamy znan «Tekhnichni nauky»), 62, 167-171.

10. Iskovich-Lototskiy, R. D., Matveev, I. B., Krat, V. A. (1982). Mashiny vibratsionnogo i vibroudarnogo deystviya. Kyiv: Tekhnika, 35-87.

11. Poturaev, V. N., Franchuk, V. P., Chervonenko, A. G. (1964). Vibratsionnye transportiruyuschie mashiny. Moscow: Mashinostroenie, 222.

12. Opanasiuk, Ye. H., Fesiuk, S. O. (2019). Doslidzhennia vplyvu vibrodii na sypki produkty roslynnytstva na enerhoiemnist rozvantazhuvannia avtomobiliv-samoskydiv. Transportni tekhnolohii. Zhytomyr, 238.

Evgen Opanasyuk, PhD, Associate Professor, Department of Vehicles and Transport Technologies, Zhytomyr Polytechnic State University, Zhytomyr, Ukraine, e-mail: opanasyukevgen@gmail.com, ORCID: https:// orcid.org/0000-0003-3367-5816

$\triangle$ Dmytro Beherskyi, PhD, Department of Vehicles and Transport Technologies, Zhytomyr Polytechnic State University, Zhytomyr, Ukraine, e-mail: begerskiy@gmail.com, ORCID: https://orcid.org/ 0000-0002-8357-0038

Mykola Mozharovskyi, Senior Lecturer, Department of Vehicles and Transport Technologies, Zhytomyr Polytechnic State University, Zhytomyr, Ukraine, e-mail: mykolamozharovskyi@gmail.com, ORCID: https:// orcid.org/0000-0002-4720-3783

Ivan Vitiuk, Senior Lecturer, Department of Vehicles and Transport Technologies, Zhytomyr Polytechnic State University, Zhytomyr, Ukraine, e-mail: vnvik74@gmail.com, ORCID: https://orcid.org/ 0000-0002-3577-8758

$\bowtie$ Corresponding author 